\title{
Synthesis and Physical Properties of Several Aliphatic and Alicyclic Hydrocarbons
}

\section{Philip Pomerantz, Abraham Fookson, ${ }^{1}$ Thomas W. Mears, Simon Rothberg, ${ }^{2}$ and Frank L. Howard}

\begin{abstract}
The synthesis and purification of four paraffins, three cycloparaffins, six olefins, and five diolefins, and their intermediates are described. These compounds were prepared by standard reactions or modifications thereof, and purified by fractional distillation. Physical properties of the hydrocarbons are presented, and purity data are given for some of them.
\end{abstract}

\section{Introduction}

At its outset the hydrocarbon research program at the National Bureau of Standards was concerned with compounds of interest as fuel components in high-compression spark-ignition engines. Therefore, the emphasis was upon highly branched paraffin hydrocarbons [8]. ${ }^{3}$ With the advent of reaction engines, the researches were directed to the syntheses of alicyclic hydrocarb ons and the less highly branched aliphatics with various degrees of unsaturation. The work on the acetylenic hydrocarbons is described in a previous paper [12]. The work described herein is the part of this program, sponsored by the National Advisory Committee for Aeronautics, dealing with the syntheses and purification of 4 paraffins, 6 olefins, 5 diolefins, and three alicyclic hydrocarbons.

\section{Apparatus}

\subsection{Reaction Vessels}

Large-scale reactions were carried out in two commercial 50-gal jacketed reaction kettles designed to permit any temperature from $5^{\circ}$ to $150^{\circ} \mathrm{C}$ to be maintained. One of these was stainless steel, the other was glass-lined steel; both are described in a previous publication [8]. In general, preparations of Grignard reagents were carried out in the stainlesssteel vessel; the more corrosive reactions, such as acid oxidations, were conducted in the glass-lined one.

For reactions involving liquid ammonia as a solvent (see sec. 4.9 and 4.10), a 10-gal stainless-steel kettle was used. This reactor was jacketed and

1 Present address, Frankl Photographic Services, Washington, D. C,

2 Present address, National Institutes of Health, Bethesda, Md.

3 Figures in brackets indicate the literature references at the end of this paper. insulated with a 6-in. layer of ground cork. There were appropriate facilities for the addition of reagents or observation of reflux. This equipment has been described previously [12].

\subsection{Hydrogenation Equipment}

Commercial rocking autoclaves of 1-, 3-, and 20-liter capacity were used for this work. A commercial nickel-on-kieselguhr catalyst was used, and the hydrogenations were usually carried out at $140^{\circ}$ to $180^{\circ} \mathrm{C}$ and at a maximum pressure of $2,500 \mathrm{lb} / \mathrm{in}^{2}$. This equipment is described in a previous publication [8].

\subsection{Dehydration Equipment}

The dehydrator consisted of a 2 - by 48 -in. stainlesssteel tube placed in a furnace made by winding $35 \mathrm{ft}$ of nichrome wire $(1 \mathrm{ohm} / \mathrm{ft})$ around a 3.25 - $\mathrm{ft}$ length of 2-in. pipe. Aluminum-oxide catalyst was contained in the tube and activated by heating for $4 \mathrm{hr}$ at $250^{\circ} \mathrm{C}$ in a stream of nitrogen. The feed of material to the apparatus was controlled either by a constant-level device made by modification of an automobile carburetor or by means of a commercial sylphon pump whose rate could be regulated. Dehydrations in this work were conducted in the vapor phase at $300^{\circ}$ to $320^{\circ}$ C. Details of the dehydrator have been given previously [11].

\subsection{Stills}

Six stills were used in this work. These have been described previously [8], but for convenience, the salient features of each are given in table 1.

TABLE 1. Distillation columns

\begin{tabular}{|c|c|c|c|c|c|}
\hline Still & Type & Size & Material of construction & Packing & Pot capacity \\
\hline $11 \ldots$ & Total reflux-variable takeoff & 240 by $\stackrel{c m}{2}$ & Monel . & \multirow{4}{*}{$\begin{array}{l}\text { 3/32-in. stainless-steel helices made from } \\
\text { 0.010-in. wire. } \\
\text { 3/8-in. unglazed-porcelain raschig rings } \\
\text { do } \\
\text { Heli-grid. } \\
\text { 3/16-in. glass helices. }\end{array}$} & \multirow{4}{*}{$\begin{array}{l}\quad m l \\
60,000 \\
210,000 \\
210,000 \\
250 \text { to } 5,000 \\
250 \text { to } 5,000 \\
22,000\end{array}$} \\
\hline 12. & do do & 1,500 by 10 & Galvanized steel & & \\
\hline 18 & Podbielniak Hypercal & 127 by $2.5_{-}$ & Glass & & \\
\hline $\begin{array}{l}19 \ldots \\
21 \ldots \ldots\end{array}$ & Total reflux-variable takeoff & $\begin{array}{l}250 \text { by } 2.5- \\
120 \text { by } 3.5 .\end{array}$ & -_._do do & & \\
\hline
\end{tabular}




\section{Methods and Techniques}

\subsection{Preparation of Grignard Reagents}

The Grignard reagents necessary for the large-scale syntheses in this work (up to 300 moles) were prepared in the 50-gal stainless-steel kettle. The details of the preparation of these reagents have been reported previously [8]. In all cases, these reagents were reacted in place.

\subsection{Reductions with Sodium in Liquid Ammonia}

For conversion of acetylenic hydrocarbons to olefins, reduction with sodium in liquid ammonia was used; the product obtained was almost exclusively the trans isomer [7]. The description of the preparation of several alkynes is given in a previous paper [12], and some of these were used in the present work. The technique used for these reactions is illustrated by the preparation of trans-2-hexene from 2-hexyne (see sec. 4.9). In order to minimize the formation of peroxide catalysts, which induce sodium-amide formation, the sodium metal was freshly cut and immediately added to the liquid ammonia.

\subsection{Determination of Physical Properties}

The properties measured on the compounds prepared included boiling point, freezing point, refractive index, and density. The methods used for the determination of these properties have been reported previously [11]. Where feasible, purities were determined on selected hydrocarbons by mass spectrometry, low-temperature calorimetry [6], or freezingcurve analysis [13]. The low-boiling compounds and some of the unsaturates were sealed under their own vapor pressure [10]. The physical properties measured on the compounds prepared in this work and on their intermediates are. sted in table 2 , along with purity determinations, where made. When the purities were measured calorimetrically, the triple point and the molar heat of fusion of the substance [6] were also obtained.

\section{Preparation of Materials}

\section{1. n-Octane}

This paraffin was prepared by hydrogenation of purified 1-octene obtained from a commercial source (see sec. 4.11 for description of the purification of the

TABle 2. Physical properties of compounds prepared

\begin{tabular}{|c|c|c|c|c|c|}
\hline Compound & $\begin{array}{l}\text { Boiling point at } 760 \\
\mathrm{~mm} \mathrm{Hg}\end{array}$ & $\begin{array}{l}\text { Freezing point } \\
\text { in air }\end{array}$ & $\begin{array}{c}\text { Density at } \\
20^{\circ} \mathrm{C}\end{array}$ & $\begin{array}{c}\text { Refractive } \\
\text { index at } 20^{\circ} \mathrm{C}\end{array}$ & Purity a \\
\hline $\begin{array}{l}\text { 3-Octane } \\
\text { 4-Methyloctane } \\
\text { 4-Ethyloctane }\end{array}$ & $\begin{array}{l}{ }^{\circ} C \\
125.668 \\
144.214 \\
142.425 \\
163.637\end{array}$ & $\begin{array}{l}\circ C \\
-56.864 \\
\text { b } \mathrm{nf} \\
-53.528 \\
\quad \text { nf }\end{array}$ & $\begin{array}{l}g / m l \\
0.70264 \\
.7205 \\
.72017 \\
.73811\end{array}$ & $\begin{array}{l}n_{D}^{20} \\
\text { 1. } 39770 \\
\text { 1. } 40630 \\
\text { 1. } 40624 \\
\text { 1. } 41506\end{array}$ & $\begin{array}{l}\text { Mole percent } \\
99.7 \text { FP }\end{array}$ \\
\hline $\begin{array}{l}\text { Methylcyclopropane } \\
\text { Ethylcyclopropane } \\
\text { Cyclobutane }\end{array}$ & 36.2 & $\begin{array}{l}\mathrm{e}-177.51 \\
\mathrm{~d}-149.60 \\
\mathrm{e}-90.59\end{array}$ & 6840 & 1.3788 & $\begin{array}{l}\text { 99. } 30 \text { LTC } \\
\text { 98. } 79 \text { LTC } \\
\text { 99. } 91 \text { LTC }\end{array}$ \\
\hline 2-Pentene (cis and trans) .-- & 36.7 & (n) & .6545 & $\begin{array}{c}\text { 1. } 3812 \\
\text { to }\end{array}$ & 99. $4 \mathrm{MS}$ \\
\hline $\begin{array}{l}\text { trans-2-hexene } \\
\text { trans-3-hexene } \\
\text { 1-Octene- } \\
\text { 4-Ethyl-2-octene } \\
\text { 4-Ethyl-3-octene }\end{array}$ & $\begin{array}{l}67.87 \\
67.15 \\
121.26 \\
163.5 \text { to } 165.0 \\
160 \text { to } 162\end{array}$ & $\begin{array}{l}-133.07 \\
-114.28 \\
-101.84 \\
\text { nf } \\
\text { nf }\end{array}$ & $\begin{array}{l}.67853 \\
.67718 \\
.71486 \\
.7531 \\
.7457\end{array}$ & $\begin{array}{l}1.39351 \\
1.39410 \\
1.40875 \\
1.4300 \\
1.4242\end{array}$ & $99.2 \mathrm{FP}^{-1}$ \\
\hline $\begin{array}{l}\text { Propadiene-10 } \\
\text { 2,3-Pentadiene-Hexadiene } \\
\text { 2-Methyl-1,3-pentadiene } \\
\text { 2,5-Dimethyl-1,5-hexadiene. }\end{array}$ & $\begin{array}{c}-34.5 \\
48.2 \\
59.46 \\
75.76 \\
114.472\end{array}$ & $\begin{array}{c}\mathrm{f}-136.56 \\
-125.72 \\
\mathrm{nf} \\
-74.829\end{array}$ & $\begin{array}{l}.6957 \\
.69115 \\
.72391 \\
.7420\end{array}$ & $\begin{array}{l}\text { 1. } 4266 \\
\text { 1. } 40386 \\
\text { 1. } 44529 \\
\text { 1. } 4287\end{array}$ & $99.13 \mathrm{LTC}$ \\
\hline $\begin{array}{l}\text { 2-Pentanol } \\
\text { 3-Pentanol-Methyl-3-octanol- } \\
\text { 4-Methyl-4-octanol }\end{array}$ & $\begin{array}{l}119.3 \\
115.5 \\
113(50 \mathrm{~mm})\end{array}$ & $\begin{array}{l}\text { nf } \\
\text { nf } \\
\text { nf }\end{array}$ & $\begin{array}{l}.8098 \\
.8207 \\
.8331 \\
.8284\end{array}$ & $\begin{array}{l}1.4065 \\
1.4111 \\
1.4298 \\
1.4316\end{array}$ & -1-1-n \\
\hline 2-Pentanone_. & 102.4 & (............ & .8095 & 1. 3903 & -.. \\
\hline 1,1-Dicarbethoxycyclobutane... & 226.3 & $\mathrm{nf}$ & 1. 0420 & 1.4351 & ... \\
\hline Cyclobutane carboxylic acid & 135 to $138(110 \mathrm{~mm})$ & -7.1 & 1. 0610 & 1. 4430 & (n) \\
\hline Cyclobutylbromide & 107.4 & - & - & 1. 4794 & $\ldots$ \\
\hline
\end{tabular}

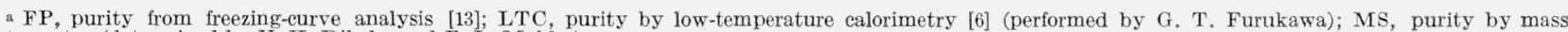
spectrometry (determined by V. H. Dibeler and F. L. Mohler).

b nf, nonfreezing, glassy at low temperatures.

c Triple point, measured in calorimeter. Molar heat of fusion $=2,800 \pm 100$ joules.

d Triple point, measured in calorimeter. Molar heat of fusion $=5,600 \pm 100$ joules.

e Triple point, measured in calorimeter. Molar heat of fusion $=5,600 \pm 100$ joules.

e Triple point, measured in calorimeter. Molar heat of fusion $=1,095 \pm 50$ joules.
$f$ Triple point, measured in calorimeter. Molar heat of fusion $=4,400 \pm 100$ joules. 
olefin). Hydrogenation of $4.32 \mathrm{~kg}$ of the 1-octene was effected smoothly, and the crude paraffin was percolated through silica gel and distilled through column 18. The center fraction was reserved for measurements of physical constants.

\subsection{3-Methyloctane}

This hydrocarbon was prepared by hydrogenation of the olefins resulting from the dehydration of 3methyl-3-octanol. The carbinol was prepared by the reaction between ethylmagnesium bromide and methyl- $n$-amyl ketone.

Ethylmagnesium bromide was prepared from 7.2 $\mathrm{kg}$ (300 g-atoms) of magnesium and $32.7 \mathrm{~kg}$ (300 moles) of ethyl bromide as described previously [8]. After preparation of the Grignard reagent, it was found that the stock of 2-heptanone was only 17.1 $\mathrm{kg}$ (150 moles) due to partial delivery of an order. This quantity was added to the Grignard reagent. In order to avoid wasting the excess Grignard reagent and to diminish the working hazards, it was decided to add $19.3 \mathrm{~kg}$ (150 moles) of 2-ethylhexaldehyde. This compound was chosen because it would yield 4-ethyl-3-octanol, a compound also needed in another synthesis. Because of the difference in molecular weight and structure, it was presumed the two final paraffins or their intermediates could easily be separated.

Six hours were required to effect the total addition, and the mixture was allowed to stand overnight. The reaction mixture was worked up in the usual manner to obtain 68 liters of ether-carbinol solution. The ether was removed from this by distillation on column 21 to leave a carbinol concentrate.

Considerable difficulty was experienced in attempting to distill the carbinol mixture. This was principally due to dehydration. Since the hydrocarbons were the desired products, it was finally decided to dehydrate the mixture of carbinols and separate the resulting olefins.

The carbinol mixture $(13.9 \mathrm{~kg})$ was dehydrated over alumina at $300^{\circ} \mathrm{C}$ during a period of $150 \mathrm{hr}$. The crude olefin was separated roughly into two fractions on columns 18 and 21. The first fraction, bp $130^{\circ}$ to $150^{\circ} \mathrm{C}$, consisted principally of 3-methyloctenes, and the second fraction, bp $150^{\circ}$ to $170^{\circ} \mathrm{C}$, principally of 4-ethyloctenes. The 3-methyloctenes fraction was redistilled to yield $5,760 \mathrm{ml}$ of material boiling $135^{\circ}$ to $150^{\circ} \mathrm{C}$. The 4-ethyloctenes fraction was redistilled to give $450 \mathrm{ml}$ of material boiling at $135^{\circ}$ to $150^{\circ} \mathrm{C}$ and $4,325 \mathrm{ml}$ of material boiling $150^{\circ}$ to $170^{\circ} \mathrm{C}$. Material of like boiling points were combined for a total of $6,210 \mathrm{ml}(4.62 \mathrm{~kg}, 36.7$ moles $)$ of 3-methyloctenes, bp $135^{\circ}$ to $150^{\circ} \mathrm{C}$, and 4,325 $\mathrm{ml}\left(3.27 \mathrm{~kg}, 23.4\right.$ moles) of 4-ethyloctenes, bp $150^{\circ}$ to $170^{\circ} \mathrm{C}$. A considerable amount of high boiling residue remained that was not investigated but was probably aldol formed from 2-ethylhexaldehyde.

A charge of the $135^{\circ}$ to $150^{\circ} \mathrm{C}$ cut was refractionated in column 19 in order to obtain samples for physical properties. However, no sharp "plateau" was obtained; the major portion boiled at $146.5^{\circ}$ to $150^{\circ} \mathrm{C}$, but the refractive index, $n_{D}^{20}$, rose from 1.4238 to 1.4258 .

The mixed 3-methyloctenes (3.5 kg, 28.2 moles) were hydrogenated, and the resulting crude 3methyloctane $(4,000 \mathrm{ml})$ was distilled in column 19 . From this distillation there was obtained $3,160 \mathrm{ml}$ of a 3-methyloctane plateau. A center portion of this had a 20 to 80 percent boiling-point spread of $0.007^{\circ} \mathrm{C}$. This was the sample chosen for the determination of the physical constants.

\subsection{4-Methyloctane}

This hydrocarbon was prepared by a series of reactions, beginning with the oxidation of 2-pentanol to the corresponding ketone. The 2-pentanone was reacted with $n$-butylmagnesium chloride to yield 4-methyl-3-octanol, which was dehydrated, and the resulting olefins hydrogenated to 4-methyloctane.

Commercial mixed secondary amyl alcohols (190 liters) were fractionated in column 11 to yield 38 liters of 3-pentanol, bp $115.3^{\circ}$ to $115.7^{\circ} \mathrm{C}, n_{D}^{20}=$ 1.4104 to 1.4106 , and 40 liters of 2 -pentanol, bp $119.1^{\circ}$ to $119.5^{\circ} \mathrm{C}, n_{D}^{20}=1.4062$ to 1.4068 .

The 2-pentanol was oxidized, using sulfuric acidsodium dicromate as the oxidizing agent [15]. Sulfuric acid $(13.8 \mathrm{~kg}$ ) was added with stirring and cooling to 30 liters of water in the glass-lined kettle. To this solution was added $16.5 \mathrm{~kg}$ (188 moles) of 2-pentanol, followed by slow addition of a solution of $18.79 \mathrm{~kg}$ of sodium dichromate in 37 liters of $4 \mathrm{~N}$ sulfuric acid. During this addition the solution was stirred and the temperature maintained at $25^{\circ}$ to $30^{\circ} \mathrm{C}$. After completion of the oxidation step, 56 liters of water was added and the solution steamdistilled until no more organic layer came over. From this operation there was obtained about 19 liters of crude ketone, which was distilled in column 21 to give 15 liters $(1.21 \mathrm{~kg}, 141$ moles, 75 percent) of 2-pentanone, bp $103^{\circ}$ to $105^{\circ} \mathrm{C}$.

$n$-Butylmagnesium chloride was prepared from $13.9 \mathrm{~kg}$ (150 moles) of $n$-butyl chloride and $3.65 \mathrm{~kg}$ (156 g-atoms) of magnesium in the conventional manner [8]. The addition of the halide required 3 $\mathrm{hr}$, followed by $2 \mathrm{hr}$ of stirring. To this was added $11.8 \mathrm{~kg}$ (138 moles) of 2-pentanone over a period of $2 \frac{1}{2} \mathrm{hr}$. The reaction mixture was treated in the usual way, and the ether stripped off in column 21 . From this reaction there was obtained about 22 liters of crude 4-methyl-4-octanol. This material was distilled in columns 18 and 19 , which gave 13.5 $\mathrm{kg}$ (93.8 moles, 68 percent) of purified carbinol, bp $105^{\circ}$ to $112^{\circ} \mathrm{C}$ at $50 \mathrm{~mm} \mathrm{Hg}$. A sample of the best material was reserved for the measurement of physical constants.

The 4-methyl-4-octanol (13.3 kg, 92.5 moles) was dehydrated by passage over alumina at $300^{\circ}$ to $320^{\circ} \mathrm{C}$ at the rate of 120 to $130 \mathrm{ml} / \mathrm{hr}$. From this step there was obtained 15.6 liters of organic layer and 1.6 liters of water (96 percent dehydration). The olefin was distilled in columns 18 and 19 , to yield 10.5 
$\mathrm{kg}$ (83.4 moles, 90 percent) of mixed 4-methyloctenes, bp $142^{\circ}$ to $150^{\circ} \mathrm{C}$. A part of the olefin was redistilled in column 19, and almost all the charge distilled over a boiling range of $144.2^{\circ}$ to $146.2^{\circ} \mathrm{C}$. This was to be expected, because the major olefins would be the very similar cis- and trans-4-methyl-3-octene and cisand trans-4-methyl-4-octene, together with a lesser amount of 2-n-butyl-1-pentene. None of the samples taken was considered sufficiently pure to warrant the determinations of physical properties.

A charge of $4.05 \mathrm{~kg}$ (32 moles) of the 4-methyloctenes was hydrogenated to give $3.92 \mathrm{~kg}$ ( 30.5 moles, 96 percent) of 4-methyloctane. Four liters of the crude paraffin was distilled in column 18 to recover $2,840 \mathrm{ml}$ of material of suitable purity.

\subsection{4-Ethyloctane}

The synthesis of the olefin precursors of this paraffin $(4,325 \mathrm{ml}$ of mixed 4-ethyl-2-octene and 4-ethyl3 -octene) is described in section 4.2. The mixture was redistilled on column 19 to yield two plateaus. The first plateau, bp $160^{\circ}$ to $162^{\circ} \mathrm{C}$, was tentatively identified as 4-ethyl-3-octene; the second plateau, bp $163.5^{\circ}$ to $165^{\circ} \mathrm{C}$, was probably cis- and trans-4-ethyl2-octene. Physical properties measured on these compounds are listed in table 2. The 4-ethyloctenes were hydrogenated, and the resulting crude paraffin was distilled through still 19 to yield 4-ethyloctane.

\subsection{Methylcyclopropane}

This cycloparaffin was prepared by the reaction of zinc with 1,3-dibromobutane, according to the method of Bartleson, Burk, and Lankelma [3]. Several runs were made; a typical preparation is described below.

A mixture of $100 \mathrm{~g}$ of water, $196.5 \mathrm{~g}$ of zinc dust (3 g-atoms), and $3,000 \mathrm{ml}$ of $n$-propyl alcohol was cooled with an ice-bath. Over a 90 -min period there was added $216 \mathrm{~g}$ (1.0 mole) of 1,3-dibromobutane to the stirred mixture. The ice-bath was then removed and the flask permitted to warm up. After reaching room temperature, the reaction mixture warmed spontaneously with a brisk evolution of gas, until the flask temperature was $60^{\circ}$ to $70^{\circ} \mathrm{C}$. When the reaction was completed, the mixture was allowed to cool to room temperature, $250 \mathrm{ml}$ water added, and a stream of nitrogen passed gently through the system for flushing. There collected in the receiver $51 \mathrm{~g}$ of product, yield 91 percent. This material was percolated through a silica-gel column kept at $-78^{\circ} \mathrm{C}$ and distilled into a brass bomb for storage. The yield from four such runs totaled $136 \mathrm{~g}$.

\subsection{Ethylcyclopropane}

This hydrocarbon was prepared by a Wolff-Kishner reduction of the hydrazone of methylcyclopropylketone [1].

To a mixture of $1,285 \mathrm{ml}$ of diethylene glycol, $473.4 \mathrm{~g}$ (5.63 moles) of methylcyclopropylketone and $25 \mathrm{ml}$ lglacial acetic acid in a 5-liter flask, was added
$656 \mathrm{~g}$ of 64-percent commercial hydrazine hydrate The solution was refluxed for about $1 \mathrm{hr}$ and then distilled through a packed column until the head temperature reached $120^{\circ}$ C. The residue was cooled and then added dropwise to a mixture (at $180^{\circ}$ to $200^{\circ} \mathrm{C}$ ) of $1,350 \mathrm{ml}$ of diethyleneglycol and $420 \mathrm{~g}$ sodium hydroxide. The decomposition products were condensed in a trap cooled to $-78^{\circ} \mathrm{C}$. The crude hydrocarbon was washed successively with water, dilute hydrochloric acid, again with water, and then dried over anhydrous sodium sulfate before distillation in column 19 . The distillate boiled $35.5^{\circ}$ to $36.5^{\circ} \mathrm{C}$ and amounted to $152 \mathrm{~g}$, yield 39 percent. This material was redistilled on column 19, and a center cut of $125 \mathrm{ml}$, bp $35.9^{\circ}$ to $36.2^{\circ} \mathrm{C}$, was chosen for measurement of physical properties and purity.

\subsection{Cyclobutane}

Cyclobutane was prepared by a series of reactions that are a modification of the procedure described by Cason and Way [6] and Cason and Allen [5]. In this method, 1,1-dicarbethoxycyclobutane was prepared from diethyl malonate and 1,3-dibromopropane by condensation. The ester was hydrolyzed and decarboxylated by heating with aqueous hydrochloric acid. 'The silver salt of cyclobutane carboxylic acid was then added to bromine in carbon tetrachloride at $-20^{\circ} \mathrm{C}$ to give cyclobutyl bromide. This was converted to cyclobutane through the Grignard reaction.

(a) 1,1-Dicarbethoxycyclobutane. To a solution prepared from $13.6 \mathrm{~kg}(85.0$ moles $)$ of diethylmalonate and $4.4 \mathrm{~kg}$ of sodium methoxide in 37 liters of absolute alcohol there was added concurrently 13.8 $\mathrm{kg}$ ( 68.5 moles) of 1,3-dibromopropane and a solution of $2.9 \mathrm{~kg}$ of sodium methoxide in 25 liters of absolute ethanol. The time of addition was $5 \frac{1}{2} \mathrm{hr}$. When the addition was completed, the reaction mixture was refluxed for 45 -min, after which the ethanol was removed by distillation. To the cooled residue was added with stirring 26 liters of water and 18 liters of isooctane ${ }^{4}$ as solvent. The two layers were separated, and the aqueous layer was stirred again with 7.6 liters of water and 7.6 liters of isooctane. The layers were again separated and the organic layers combined and dried over anhydrous sodium carbonate. The solvent and other low-boiling material were stripped off in columns 18 and 19 . The residues were combined and distilled under reduced pressure in column 6 . The fraction boiling at $125^{\circ}$ to $133^{\circ} \mathrm{C}$ at $50 \mathrm{~mm} \mathrm{Hg}$ was collected as 1,1-dicarbethoxycyclobutane. The yield was $7.38 \mathrm{~kg}$ (54 percent).

The residue was a very high-boiling material and was not treated further. It probably consisted of 1,1,5,5-tetracarbethoxypentane.

(b) Cyclobutane carboxylic acid. The ester was hydrolyzed and decarboxylated in 12 identical runs. In each, a mixture of $900 \mathrm{ml}$ of water, $1,800 \mathrm{ml}$ of concentrated hydrochloric acid, and $600 \mathrm{~g}$ (3 moles) of 1,1-dicarbethoxycyclobutane was refluxed until

${ }^{4}$ Isooctane is the trivial name for 2,2,4-trimethylpentane. 
the mixture became homogeneous. This took 3 to $4 \mathrm{hr}$. The water and acid were then distilled, using a short rectifying column. When all the aqueous material was removed, the residue was heated more strongly until the temperature at the head of the column reached $185^{\circ} \mathrm{C}$. The evolution of carbon dioxide proceeded smoothly and was complete in less than $1 \mathrm{hr}$.

The residues from all the runs were combined and distilled in column 18 . The portion boiling at $135^{\circ}$ to $138^{\circ} \mathrm{C}$ at $110 \mathrm{~mm} \mathrm{Hg}$ was collected as cyclobutane carboxylic acid. The yield was $2,681 \mathrm{~g}$ (74 percent).

(c) Cyclobutyl bromide. This compound was prepared by a series of several similar reactions. Because of its instability, the silver salt was prepared, dried, and reacted with bromine as rapidly as possible.

To a mixture of $200 \mathrm{~g}$ ( 2 moles) of cyclobutane carboxylic acid in $560 \mathrm{ml}$ of water was added with vigorous stirring $2 \mathrm{~N}$ potassium-hydroxide solution until the solution was faintly basic. To this was added slowly $344 \mathrm{~g}$ (2.02 moles) of silver nitrate in $1,100 \mathrm{ml}$ of water. A thick white precipitate of silver cyclobutane carboxylate was obtained. This was stirred for about $1 \mathrm{hr}$ and then filtered. The precipitate was returned to the reaction vessel, stirred with $1,600 \mathrm{ml}$ of water for $1 / 2 \mathrm{hr}$, and again filtered with suction until dry. The final precipitate was washed with methanol, dried by suction again, and then placed in an oven at $100^{\circ}$ to $110^{\circ} \mathrm{C}$ for 24 $\mathrm{hr}$. The silver salt was then cooled in a desiccator over phosphorous pentoxide.

To 2,000 $\mathrm{ml}$ of anhydrous carbon tetrachloride cooled to $-25^{\circ} \mathrm{C}$ was added the stoichiometric quantity of bromine for reaction with the silver salt. To this was added the previously prepared silver salt over a period of $1 \frac{1}{2}$ to $2 \mathrm{hr}$, keeping the temperature at $-20^{\circ}$ to $-25^{\circ} \mathrm{C}$. The solution was stirred at this temperature for $1 \mathrm{hr}$ and then slowly warmed to room temperature. The precipitated silver bromide was filtered off with suction and washed with carbon tetrachloride. The filtrate was washed with $2 N$ potassium hydroxide and with water and then dried with calcium chloride. The solvent was removed, using column 6 , and the residue from this operation was distilled through a $1.2-$ by $25-\mathrm{cm}$ Hempel column packed with glass helices.

This reaction is peculiar in that an occasional run failed to yield cyclobutyl bromide. It was noted in the successful runs that during the warming-up period of the bromination step, there was a sharp rise in temperature at about $-10^{\circ} \mathrm{C}$. This break was not evident in runs in which no yield was obtained. The average yield on the successful runs was 43 percent.

The crude cyclobutyl-bromide samples were combined, washed with water, dried with sodium carbonate, and distilled in column 19 . A total of $754 \mathrm{~g}$ of purified cyclobutyl bromide was obtained.

(d) Cyclobutane. To $48.6 \mathrm{~g}$ (2 moles) of magnesium turnings were added $100 \mathrm{ml}$ of dibutyl ether and $6.7 \mathrm{~g}$ cyclobutyl bromide. The flask was warmed to $60^{\circ} \mathrm{C}$ in a water bath until the reaction started. To this was added over a period of $3 \mathrm{hr} 264 \mathrm{~g}$ (1.96 moles) of cyclobutyl bromide in $1,250 \mathrm{ml}$ of dibutyl ether. The mixture was stirred for $1 \frac{114}{4} \mathrm{hr}$ at $55^{\circ}$ to $60^{\circ} \mathrm{C}$, after which it was cooled with ice, and $460 \mathrm{ml}$ of $n$-butyl alcohol added slowly. When the addition was complete, the temperature of the mixture was raised slowly until reflux temperature was reached. The escaping gas was passed through the water condenser, an 85-percent sulfuric-acid wash, a 5percent potassium-hydroxide wash, and a calciumchloride drying tower, and condensed into a receiver at $-30^{\circ} \mathrm{C}$. The reaction vessel and purification train were flushed out with dry nitrogen. The yield of cyclobutane in this step was $94 \mathrm{~g}$ (84 percent).

From three runs there was obtained a total of 252 $\mathrm{g}$ of cyclobutane (about 85-percent yield). The combined samples were fractionated through column 18 and sealed in vacuum [10].

\subsection{2-Pentene}

This olefin was prepared by the dehydration of 3-pentanol, obtained by fractionation of a commercial alcohol mixture (see sec. 4.3). A total of 3,080 $\mathrm{ml}$ of purified 3-pentanol was passed over the alumina at $300^{\circ}$ to $320^{\circ} \mathrm{C}$. There was obtained $2,850 \mathrm{ml}$ of organic material and $438 \mathrm{ml}$ of water. The amount dehydrated, based on water recovered, was 86 percent. The organic layer was washed with water, dried over anhydrous sodium carbonate, and distilled in column 19. The center cut was selected for measurement of physical properties and purity shown in table 2 for this compound.

\section{9. trans-2-Hexene}

This compound was prepared by reduction of 2-hexyne with sodium in liquid ammonia. The 2-hexyne was prepared by alkylation of acetylene, and its synthesis is described in a previous paper [12]. The reduction yielded trans-2-hexene almost exclusively, in 69-percent yield.

To $10 \mathrm{~kg}$ of liquid ammonia $(200 \mathrm{~g} /$ mole of reactant) in the 10-gal stainless-steel kettle was added with stirring $1,220 \mathrm{~g}$ (53 g-atoms) of sodium. No violent exothermic reaction was evident; the sodium dissolved and colored the ammonia a deep blue. The 2-hexyne (1,917 g, 23 moles) was then added as rapidly as the condenser capacity permitted. The solution was allowed to stir for $1 / 2 \mathrm{hr}$ after all the material was added, then $6 \mathrm{lb}$ of solid ammonium chloride $(50.5$ moles $)$ was added in portions to destroy the sodium amide formed. The contents of the pot were stirred for $15 \mathrm{~min}$, after which 5 -gal of water was slowly added with stirring. After the layers settled, the organic layer was washed three times with water and dried over anhydrous sodium carbonate.

Distillation of the organic layer on still 19 yielded a $2,000-\mathrm{ml}$ fraction boiling $67^{\circ}$ to $69^{\circ} \mathrm{C}$ (yield 69 percent). The physical constants measured on a center cut of the final distillation are reported in table 2 . 


\subsection{0. trans-3-Hexene}

This compound was prepared by reduction of 3hexyne with sodium in liquid ammonia, as described in section 4.9 for trans-2-hexene. For this preparation there was used $8 \mathrm{~kg}$ of liquid ammonia, 1,143 $\mathrm{g}$ of sodium (50 g-atoms), 1,904 g (23.2 moles) of 3hexyne, and $2.8 \mathrm{~kg}$ ( 52 moles) of ammonium chloride. The dried organic layer from this run was distilled in column 19 to give $1,608 \mathrm{~g}$ (19.2 moles) of product, bp $67^{\circ}$ to $68^{\circ} \mathrm{C}$. This corresponds to 82 -percent yield. The physical properties measured on a middle cut of this compound are given in table 2 .

\subsection{1-Octene}

This compound was obtained in high purity by careful fractionation of commercial 1-octene. Distillation of $4,000 \mathrm{ml}$ of the crude olefin on column 19 gave $3,500 \mathrm{ml}$ of 1-octene with the properties listed in table 2. A portion of the purified 1-octene was hydrogenated to yield $n$-octane (see sec. 4.1).

\subsection{Propadiene}

This diolefin was made from the reaction of zinc with 2,3-dichloro-1-propene in methylcellosolve. When this dechlorination was attempted in ethanol [9], no reaction took place.

To a 3-liter flask equipped with stirrer, addition vessel and reflux condenser was added $300 \mathrm{~g}$ of zinc dust and $1,000 \mathrm{ml}$ of methylcellosolve. To this mixture at its boiling point $\left(135^{\circ} \mathrm{C}\right)$ was added dropwise $325 \mathrm{~g}$ (3 moles) of 2,3-dichloro-1-propene. There was an immediate reaction and sufficient evolution of heat to maintain the mixture at its boiling point with the heating mantle removed. The evolved gases were collected in a flask cooled to $-78^{\circ} \mathrm{C}$. The yield from three such runs was $180 \mathrm{~g}$ (50-percent yield). The product was dissolved in $500 \mathrm{ml}$ of $n$-pentane and distilled in column 19. The fraction boiling at $-34.5^{\circ} \mathrm{C}$ was reserved for measurements of the physical properties listed in table 2 .

\subsection{2,3-Pentadiene}

This compound was obtained by fractional distillation of a sample obtained from a commercial source.

Distillation of $3,000 \mathrm{ml}$ in column 19 yielded a middle cut of $2,200 \mathrm{ml}$, bp $48^{\circ}$ to $49^{\circ} \mathrm{C}$. The properties of this material are reported in table 2.

\subsection{2-Methyl-1,3-Pentadiene}

This diolefin was prepared from the dehydration of 4-methyl-2-pentene-4-ol.

To prepare the starting material (ethyl crotonate) for this synthesis, a mixture of $5,326 \mathrm{~g}$ (62 moles) of crotonic acid, 18.5 liters of 95-percent ethanol, and $172 \mathrm{ml}$ of concentrated sulfuric acid was heated at $95^{\circ} \mathrm{C}$ in the glass-lined kettle for $8.5 \mathrm{hr}$. After the mixture had cooled, the contents of the kettle were diluted with 34 liters of water; the organic layer was washed with sodium carbonate solution and then dried over anhydrous sodium carbonate. Distillation of this crude gave $3.47 \mathrm{~kg}$ of ethyl crotonate, bp $137^{\circ}$ to $137.5^{\circ} \mathrm{C}$, yield 50 percent.

The ethyl crotonate $(3.47 \mathrm{~kg}, 30$ moles) was reacted for 2 days at reflux temperature with methylmagnesium bromide made from $7.5 \mathrm{~kg}$ of methyl bromide (79 moles) and $1.92 \mathrm{~kg}$ of magnesium (79 g-atoms) in 24 liters of ether. At the end of this time, 3 gal of water was added, the ether layer siphoned, washed once with water, and dried over sodium carbonate. The sludge was treated with 11 gal of water containing $9.5 \mathrm{~kg}$ of ammonium chloride; the resulting organic layer was washed until neutral to litmus and added to the main batch. The combined ether solution was distilled at atmospheric pressure on column 21. After the ether was stripped, dehydration of the carbinol started at a head temperature of $65^{\circ}$ C. When the distillate temperature continued to rise and reached $78^{\circ} \mathrm{C}$, the column was placed on total reflux until the temperature fell to $65^{\circ} \mathrm{C}$; the takeoff was then continued until a head temperature of $78^{\circ} \mathrm{C}$ was reached. At this point the column was placed on total reflux again. The operation of the still in this manner between the head temperatures of $65^{\circ}$ to $78^{\circ} \mathrm{C}$ resulted in the dehydration of the carbinol and distillation of the diolefin. About 2 liters of crude diolefin boiling $65^{\circ}$ to $78^{\circ} \mathrm{C}$ was obtained. This material was dried and redistilled in column 18 to obtain $1,710 \mathrm{ml}$ of material boiling $74^{\circ}$ to $77^{\circ} \mathrm{C}$. For the final pure material needed for this work, the $74^{\circ}$ to $77^{\circ}$ fraction was redistilled on column 19 under an atmosphere of nitrogen. A center cut was then bottled in vacuum.

The physical constants measured on this compound are listed in table 2 . The extremely narrow boiling range of the center-cut sample $(0.011 \mathrm{deg} C)$ indicates this material to be of high purity. Chemical tests were used to establish the identity of this diolefin. Treatment with maleic anhydride according to the method of Bachman and Goebel [2] gave a 98-percent yield of 3,5-dimethyl- $\Delta^{4}$ tetrahydrophthalic anhydride, $\mathrm{mp} 57^{\circ} \mathrm{C}$. Oxidation of the diolefin with potassium permanganate [2] did not yield acetone, which would arise from the presence of isomeric 4-methyl-1,3-pentadiene, a compound that could be formed in the dehydration process and would be inseparable by ordinary fractional distillation.

\subsection{1,5-Hexadiene}

This compound was prepared by the reaction of allyl chloride with magnesium [14]. Two identical 200 -mole runs were made in the 50 -gal stainless-steel reactor, in each of which $15.2 \mathrm{~kg}$ (200 moles) of allyl chloride, $2.82 \mathrm{~kg}$ (116 moles) of magnesium, and 60 liters of ether were used. The combined product, after distillation on column 11 (bp $56^{\circ}$ to $63^{\circ} \mathrm{C}$ ), amounted to $11.31 \mathrm{~kg}$ (138 moles), yield 69 percent. A 2,000-ml portion of the crude hydrocarbon was redistilled on column 19 at a reflux ratio of 100 to 1 , under nitrogen, to obtain a pure sample for the determination of the physical properties. 


\subsection{2,5-Dimethyl-1,5-Hexadiene}

This compound was prepared by the reaction of methallyl chloride with magnesium.

To the stainless-steel kettle was added $778 \mathrm{~g}$ (32 g-atoms) of magnesium and about 4 liters of ether. About $200 \mathrm{ml}$ of methallyl chloride was then added, along with a few crystals of iodine to start the reaction. The remainder of the ether (14 liters) was added when the reaction was well under way, following which the addition of the remaining methallyl chloride (total $6.0 \mathrm{~kg}, 65$ moles) was accomplished in $1 \mathrm{hr}$. The mixture was allowed to stand over night, and the product recovered in the usual way. Distillation on still 6 yielded $2.94 \mathrm{~kg}$ of 2,5 -dimethyl1,5-hexadiene, yield 75 percent.

\section{Conclusions}

Four paraffins, 6 olefins, 5 diolefins, and 3 alicyclic hydrocarbons have been prepared in high states of purity for use in jet-fuel researches. The details of the syntheses and the purification process are given, along with the physical properties measured on the hydrocarbons and their intermediates.

We thank D. B. Brooks, R. L Alexander, J. A. Cogliano, and E. H. Rich for their advice and assistance in preparing some of the compounds made in this work.

Acknowledgment is made to G. T. Furukawa of the Thermodynamics Section for determining the purity of some of these hydrocarbons by low-temperature calorimetry, and to V. H. Dibeler and F. L.
Mohler of the Bureau's Mass Spectrometry Section who performed the mass spectrographic analyses reported.

\section{References}

[1] American Petroleum Institute Research Project 45, monthly report (April 1947).

[2] G. B. Bachman and C. G. Goebel, J. Am. Chem. Soc. 64, 787 (1942).

[3] J. D. Bartleson, R. E. Burk, and H. P. Lankelma, J. Am. Chem. Soc. 68, 2513 (1946).

[4] J. Cason and C. F. Allen, J. Org. Chem. 14, 1036 (1949).

[5] J. Cason and R. L. Way, J. Org. Chem. 14, 31 (1949).

[6] G. T. Furukawa, D. C. Ginnings, R. E. McCoskey, and R. A. Nelson, J. Research NBS 46, 195 (1951) RP2191.

[7] A. L. Henne and K. W. Greenlee, J. Am. Chem. Soc. 65, $2020(1943)$.

[8] F. L. Howard, T. W. Mears, A. Fookson, P. Pomerantz, and D. B. Brooks, J. Research NBS 38, 365 (1947) RP1779.

[9] G. B. Kistiakowsky, J. R. Ruhoff, H. A. Smith, and W. E. Vaughn, J. Am. Chem. Soc. 58, 146 (1936).

[10] B. J. Mair, D. J. Termini, C. B. Willingham, and F. D. Rossini, J. Research NBS 37, 229 (1946) RP1744.

[11] T. W. Mears, A. Fookson, P. Pomerantz, E. H. Rich, C. S. Dussinger, and F. L. Howard, J. Research NBS 44, 299 (1950) RP2079.

[12] P. Pomerantz, A. Fookson, T. W. Mears, S. Rothberg, and F. L. Howard, J. Research NBS 52, 51 (1954) RP2472.

[13] Selected values of properties of hydrocarbons, Cir. NBS 461 (1947).

[14] A. Turk and H. Chanan, Org. Syntheses 27, 7 (1949).

[15] G. R. Yohe, H. U. Louder, and G. A. Smith, J. Chem. Educ. 10, 374 (1933).

Washington, August 19, 1953. 